\title{
Chapter 1 \\ Migrants with Irregular Status in Europe: A Multi-faceted and Dynamic Reality
}

\author{
Anna Triandafyllidou and Sarah Spencer
}

\subsection{Introduction}

This book explores the conceptual challenges posed by the presence of migrants with irregular immigration status in Europe and the evolving policy responses at the European, national, and municipal levels. Set in the context of recent patterns of migration and residence of migrants with differing forms of irregular status, this edited collection addresses the conceptual and policy issues raised, post-entry, by this particular section of the migrant population. This volume seeks thus to go beyond a vision of irregular migration as a crisis or a temporary emergency. By contrast, we look at the continuity of the phenomenon, its different facets and how they evolve as we seek to offer new conceptual tools for better understanding a complex reality.

Digging beneath common assumptions and polarised discourse, the book highlights the shades of grey that have been revealed by empirical findings of social realities such as the contrast between dominant representations of illegality and the actuality of semi-inclusion, or the tensions and trade-offs in policy responses that reflect competing policy objectives. In this volume we explore irregularity as a structural characteristic of contemporary western societies but yet fluid in its forms and implications. We conceptualise irregularity as a multi-faceted status with life changing implications for individuals as well as a driver of innovative policy change that has created friction in multi-level governance relationships particularly between local and national authorities.

\footnotetext{
A. Triandafyllidou $(\bowtie)$

Department of Sociology, Faculty of Arts, Ryerson University, Toronto, ON, Canada e-mail: anna.triandafyllidou@ryerson.ca
}

\section{S. Spencer}

Centre on Migration, Policy and Society, University of Oxford, Oxford, UK

e-mail: sarah.spencer@compas.ox.ac.uk 
Necessarily multi-disciplinary in approach, contributions to this volume take the reader through philosophical and ethical dilemmas, legal and sociological analysis to questions of public policy and governance before addressing the concrete ways in which those questions are posed in current policy agendas, from the international to the local level.

Given the variety of situations that the label 'irregular status' entails and the different policy approaches as well as practices on the ground, this book gathers evidence from different parts of Europe. Different chapters complement each other through a deep dive into European regional and country case studies and a focus on key sectors of the labour market, conveying the breadth of significance of the issue while recognising significant differences in the forms of and responses to irregularity in different States and localities.

Irregular migration is a multifaceted, dynamic phenomenon that attracts disproportionate media and political attention. Migrants represent 3.5\% of the world's population — notably a rather small fraction — and of those, according to recent estimates, migrants in an irregular situation represent between $15 \%$ and $20 \%$. This would thus mean approximately $1 \%$ of the total world population, which still would involve 30-40 million individuals worldwide (UN OHCHR 2014; ILO 2015). Naturally such figures are estimates and vary among continents. Irregular migration is pervasive in some sectors and areas of Asia and Africa, reaching and exceeding $50 \%$ of the migrant population. It is quite extensive in North America (according to Rosenblum and Ruiz Soto's 2015 estimate there were 11 million irregular migrants in the US in 2013) but quite limited in Europe, where the most recent comparable estimates (Kovacheva and Vogel 2009) put the number of irregular migrants between 1.9 and 3.8 million in 2008 while a decade letter the Pew Research Centre (2019) estimates the same number to be between 2.9 and 3.8 million. There are reasons to believe that irregular migration may have slowed during the economic and financial crisis in Europe and the United States, a trend that might have been partially reversed due to the most recent developments affecting asylum-seeking and irregular migration to Europe from both Africa and Asia. It is nonetheless remarkable that the highest number in the estimates' range has remained rather stable despite the 2010s having been a turbulent decade.

Irregular migration involves different types of irregularity—legal entry and irregular stay, entry with fake documents, entry and abuse of the terms of stay, to name a few. However as irregular migrants are human beings like anyone else, they are active in both the public and private space: they find employment (usually without appropriate documents) and accommodation, have families, health and education needs; sometimes they actively contribute to their communities despite their irregular status, and advocate for policy change. They thus pose multiple governance, political, and moral challenges at the local, national, and European levels.

Our theoretical understandings of irregular labour migration can still be summarised largely in what Portes (1978) called the 'structural determinants in both sending and receiving countries': that is, the demand for cheap, irregular labour in receiving countries coupled with the demographic and economic pressures of booming young populations in sending countries. Restrictive policies 'generate' illegal residence status and irregular work to the extent that they make it very difficult for 
both migrants and their employers to regularise their situation as they have two hurdles to overcome: migration legislation and labour law. Patterns of irregularity have increasingly diversified over time, including children born of undocumented parents, visa over-stayers and migrants who lost their legal status because of unemployment/non-compliance with some of the law's requirements, and rejected asylum seekers. As migrating legally to the EU and other western countries has become increasingly difficult, some have argued that irregularity can be a part of a labour market strategy that provides for a cheap and plentiful workforce for some sectors of the domestic labour market until some manage to regularise their status and remain (Jordan and Düvell 2002).

During the last decade, Europe has experienced two large indirect regularisation waves through the successive Enlargements to the East, in 2004 and 2007. Citizens of 'new' member states who were irregularly residing/working in the 'old' member states, through becoming EU citizens, could then shift to a regular stay with full socio-economic and labour rights. This change from irregular to regular residence did not automatically translate into jobs in the formal economy. Nevertheless, enlargements have significantly reduced the presence of irregular migrants within the EU, thus reducing the pool of people potentially involved in irregular employment because they had no right to stay/work in the EU.

The current volatile geopolitical context since the Arab spring and protracted conflicts in the Middle East and North Africa, coupled with the fragile recovery from the global financial and Eurozone crisis, creates a particularly dynamic environment within which the temptation of irregular forms of employment for both employers and foreign workers is high. On the one hand, we are likely to be facing a growing pool of people with uncertain migration/asylum status who cannot work legally. This pool includes irregular migrants (who entered illegally or with fake documents) and rejected asylum seekers. On the other hand, there is also a growing pool of people with tolerated or short-term legal status, people who do not have the necessary administrative knowledge to apply for a work permit, asylum seekers whose application is being processed, irregular migrants who cannot be returned to their countries of origin, and people with some sort of temporary or indeterminate status. In addition, in many European countries there continues to be a strong demand for cheap labour in several sectors of the economy, where irregular employment can contribute to savings and more flexibility for the employers, thus increasing their competitiveness. In a context of the economic fragility of many European countries, labour law reforms to reduce labour costs and increase flexibility rather than investments in re-structuring and boosting productivity are being implemented at a sustained pace (as in France, Italy, Portugal, and beyond).

\subsection{Evolving Conceptual and Policy Challenges}

In this complex reality of different types of irregularity and contrasting social and economic interests and forces around irregular migrant stay and work, we have observed competing imperatives leading to trade-offs in policymaking and the 
emergence of a complex, multi-polar and multi-level process of governance. The process is multi-polar in the sense that it involves different actors such as enforcement agents, employers, trade unions, citizen groups, migrant associations, academics and experts and, of course, the media.

It is multi-level because its governance materialises at the local level, under national and transnational (European) rules, with a high degree of discretion (as often happens in many types of public policies) at the street-bureaucracy level. In addition, we witness the emergence of different types of actors competing with the national state for legitimacy and authority in this field. These include local authorities — notably cities and towns — as, more often than not, irregular migrants reside in urban centres. It is local authorities that are faced directly with the challenges of providing services and ensuring the respect of their fundamental rights while at the same time guaranteeing public order and social cohesion. The realities of providing shelter and access to basic health services, guaranteeing education for children, ensuring the right to family unity and a family life for migrants in an irregular situation, often contrast with rigid national regulations sanctioning irregular residence and requiring expulsion orders or indeed removal of irregular migrants and their families. Local and regional authorities are among the actors that have challenged national policies in the courts, contributing (with judicial activism and civil society test cases) to an evolving jurisprudence and intervention by human-rights monitoring bodies at national, European, and international levels. The semi-inclusion that emerges raises questions about our notion of citizenship_part of the conceptual framework on this issue that the contributions to this book explore.

The local challenges of irregular migration are also acutely felt by civil society actors. There are a number of civil society organisations that work to provide assistance and shelter to irregular migrants and particularly to minors and families. At the same time there are far-right groups emerging that seek to prevent such work and engage in campaigns of intimidation and stigmatisation of irregular migrants (or migrants and asylum seekers in general).

It is our contention that there are therefore important developments at the social, economic, political, legal, and policy levels which concern the realities on the ground of irregular migrants, their work, and their civic involvement as well as the modes of governance operated by local, national, and European actors to manage irregular migration.

This book complements a longer literature addressing irregular migration in Europe by pointing to recent developments relating to migrants post-entry. The situation of irregular migrants in Europe is in transition and the first key feature of this book is its focus on change-on highlighting new conceptual analyses that have emerged to help explain this rapidly changing and complex phenomenon. Likewise, it focuses not on law or policy per se but on evolving legal and policy frameworks, their drivers, diverse actors, and potential future scenarios. It is a text that not only informs the reader on the current situation but prepares for what is to come and thus seeks to build onto earlier literature such as Triandafyllidou (2010) that offered a first overview of the size and characteristics of irregular migration in Europe, and Bommes and Sciortino (2011) that delved into the connection between irregular migration, labour markets, and welfare states in Europe. 
While much of the earlier literature focuses on illegal entry and managing irregular flows - a focus reinforced by the recent Mediterranean crossings and the whole 'refugee emergency' of the post-2015 period-this book concentrates on the situation post-entry: on irregular migrants in situ not in transit. It thus throws greater light on conditions within Europe which lead to irregular entry or stay, redressing a necessary but over-emphasised focus on 'push factors.'

This book also offers the missing link between earlier studies on the mediumand long- term challenges of irregular migration in Europe and the most recent emphasis on the refugee emergency of 2015-2017 and the particular challenges that this has raised. It thus offers a medium-term perspective, integrating the recent findings into past analyses and discourses. While the recent 'refugee emergency' may absorb significant policy and scholarly attention, if we take a step back and look at it within its wider context, it is inscribed in an already dynamic landscape of contradictory (at times) policies, uncertain or incomplete statuses, and informal but very real participation of irregular migrants in the economy and in society.

This book is not the first to focus on the tension between exclusion and inclusion. Bommes and Sciortino wrote in the conclusion to Foggy Social Structures that 'the most interesting feature of irregular migration is the evidence it provides about the condition of being fully excluded from the political system and yet still having the ability to participate in a wide range of social interactions' (2011:220). In the intervening years since its publication, new forms of that tension have emerged within national legal frameworks and in municipal practices, as has empirical evidence on the social implications and analysis within academia, which this book reflects.

\subsection{Contents of This Book}

The volume starts with a discussion of what is irregularity. Bartolini and Triandafyllidou (Chap. 2) conceptualise irregular migration status as a continuum of grey areas or of degrees and types of irregularity, rather than a clear black and white distinction. The chapter thus sets the framework for understanding terms such as 'befallen regularity' and 'semi-legality'. The authors look at irregular migration and irregular stay or work as inter-related phenomena embedded in the labour market dynamics of European countries. They thus highlight the administrative rules and labour market conditions that can foster irregularity and create these spaces in-between where irregular migrants are positioned; and further seek to provide an estimate of the irregular migrant population in Europe. The chapter concludes by discussing why people with irregular status strive to remain in Europe despite the hardship they face by briefly investigating the challenges of (sustainable) return. This essentially introductory chapter concludes by highlighting the links between irregular migration and employment.

Further casting light on the complex dynamics of irregular stay, irregular work, and informal citizenship, Sébastien Chauvin and Blanca Garcés-Mascareñas (Chap. 3 ) look at the 'moral economy' of migrant irregularity. The authors point to the fact 
that in spite of their rhetorical emphasis on enforcement, national governments have overseen a process of formal semi-inclusion of irregular migrants. That process has been taken further at regional and municipal levels. Chauvin and Garcés-Mascareñas explore the implications of that tension between formal exclusion and formal inclusion in two different ways. First, this apparent paradox allows us to deepen our understanding of the drivers and inherent trade-offs in the development of migration policies. Against unilaterally repressive theories, the authors argue that, in the area of migration, the State is confronted with contradictory imperatives and, ultimately, its various components have to choose whether to exclude those not recognised as legitimate members or embrace the population as it is. Second, by unveiling the new moral economy of migrant illegality (that is, the contemporary discourse-policy nexus regulating the construction of irregular migrants as more or less illegal) this chapter reconsiders the notion of citizenship beyond dichotomous frameworks based on binary oppositions between citizens vs non-citizens, formal vs informal, national vs local or legal exclusion vs performative acts of inclusion.

The contradictions of a moral economy of irregularity are further discussed by Colm O'Cinneide in Chap. 4 on the human rights of irregular migrants. O'Cinneide argues that human rights law is meant to provide comprehensive protection for the fundamental rights of all individuals, but this universalist aspiration is heavily qualified when it comes to migrants with irregular status, despite their marginalisation and vulnerability. Various factors play a role in limiting the reach of human rights law in this context, including States' resistance to giving effect to certain international human rights guarantees and other 'external' constraints; 'internal' factors such as a dilution of the relevant standards when it comes to applying them to irregular migrants; and the underdevelopment of human rights law in certain key respects. However, despite these limitations, the author argues that human rights standards can still provide an important platform for challenging exclusionary policies directed against irregular migrants. The chapter highlights how such claims are increasingly being used as levers by various political actors to subject such policies to political and legal contestation, with a recent example being how Dutch municipalities have invoked the provisions of the European Social Charter to challenge central government policies that imposed substantial constraints on irregular migrants accessing shelter and other forms of basic social support.

Turning to what is happening on the ground beyond normative expectations, Nicola Delvino (Chap. 5) looks at whether the European 'fortress' is slowly crumbling. This chapter outlines the evolution of EU and national legislation and policies responding to the presence of irregular migrants in Europe. It describes how the legal and policy responses of the EU and its member states have evolved around a predominantly 'exclusionary approach' towards irregularly-staying migrants that has contributed to building of 'Fortress Europe'. Besides the evolution of the EU immigration acquis, this chapter explores national developments in policy domains other than immigration legislation, including criminal law and social policies, aimed at marginalising irregular migrants to encourage their departure. However, as totally exclusionary policies have not succeeded in their ultimate goal of eradicating the presence of irregular migrants, European countries have partially re-thought their approach to take account of that presence and the social needs arising from it. 
Against an over-arching, continuing exclusionary focus in law and policy, the author identifies a more recent counter-trend of policies slowly but increasingly showing instances of inclusion of irregular migrants, such as cases of de-criminalisation of irregular migration or extension of access to services and victim support for migrants with irregular status.

With regard to civil society mobilisation, Milena Chimienti and John Solomos (Chap. 6) explore the significance of the transnational mobilization of irregular migrants. The authors investigate why and how transnational collective action is taken by people in situations of vulnerability, not least how those with limited resources manage to mobilize at the transnational level. This core argument is illustrated through the investigation of one particular event that occurred in 2012, the European March of sans-papiers and migrants. The authors explore how the movement was triggered, how it was organized, what claims were made, and what impact it had. They argue that the movement was subversive in three different ways: irregular migrants sought to act like any other citizen; they questioned the boundaries of the nation state; and they refused to be defined and limited by the global social order. The chapter shows that the transnational character of the mobilization is closely related to the root of the problems it sought to address such as European migration policies. It also illustrates how mobilization at a transnational level reinforces the social movements of 'irregular migrants'.

The contradictions of policy discourses, policy responses, and their implementation is further investigated by Ilker Ataç and Theresa Schütze in Chap. 7, 'Crackdown or Symbolism?', an analysis of post-2015 policy responses towards rejected asylum seekers in Austria. The authors draw our attention to recent developments in Austria during the 2015 emergency when the country saw a significant number of asylum seekers transit and many eventually staying in the country. In late 2015, the Austrian federal government changed its short-dated policy of waving tens of thousands of migrants through uncontrolled borders and instead prioritized a tough stance towards asylum seekers. Simultaneously, there was a shift in the Austrian approach towards rejected asylum seekers and return enforcement became an increasingly dominant issue. On the one hand, the federal government introduced a series of restrictive policy responses, aimed mainly at gaining control of these individuals through various forms of confinement. On the other, a number of symbolic policies emerged, aimed merely as a signal to the electorate of the government's restrictive and effective action against rejected asylum seekers. Based on qualitative content analysis of parliamentary documents and media coverage of policies towards this group of irregular migrants, the authors show how a mix of symbolic and substantive policy responses emerged and discuss factors that stimulated this policy strategy.

Turning to long-term factors that shape irregular migration, Chap. 8 (Triandafyllidou and Bartolini) delves deeper into the connections between irregular migration and irregular work. Indeed, the links between irregular or undeclared work and irregular migration often combine in an explosive mix that stirs anxieties about the State's control over migration flows, labour market regulation, unfair competition with native workers and lost (tax) revenue. The chapter discusses the different types of irregular employment and irregular migration and the intersection between the two to construct a typology of irregular employment of irregular foreign 
residents. The authors further investigate the dynamics of specific labour market sectors where irregularities in employment thrive, notably in domestic and care work, agriculture and the construction sector. The chapter adopts a double comparative European perspective, surveying findings from different countries, notably the Nordic countries, the UK, the Netherlands, Germany, and Italy with a focus on the different sectors, thus highlighting the role of (irregular) migrant workers within each sector and the related socio-economic and policy dynamics. The chapter concludes with a reflection on the role of enforcement and sanctions versus a variable geometry of regulation for specific labour market sectors.

The economic or labour aspects of irregular migration are discussed also in Chap. 9 (Bartolini, Mantanika, and Triandafyllidou), focusing more specifically on the economy of migrant and asylum seeker reception that has emerged in the post-2015 period. The authors explore how the recent surge in irregular flows across the Mediterranean has fostered the emergence of new economies of reception that transforms irregular migration from a challenge for border regions to an opportunity or even a strategy for survival. The chapter starts by discussing the available literature on the economies of migration control and the interlinked aspect that can be conceived as the economies of reception. The authors rerview the different types of emergency and longer-term EU funding directed to the reception and processing of migrants arrived by sea and by land in Italy and Greece, and explore the interplay between the different levels of governance and the related challenges that arise. Looking at the related emergence of local reception economies, the chapter discusses the reception system structures in Greece and Italy, their further impact in local contexts through the employment of reception-related professionals and the "refugeeization" of local labour markets, and through the (often informal) insertion of migrants with different combinations of residence and work statuses. It is the authors' contention that, through the channelling of local and regional resources, migrants arriving through irregular channels create a whole set of economic activities, occupations, and types of professional and increase or transform the employment of both locals and settled migrants.

The importance of the local level of governance for irregular migrants in Europe and the challenges and tensions between cities and the state level cannot be overestimated. In Chap. 10, 'Cities Breaking the Mould? Municipal Inclusion of Irregular Migrants in Europe', Spencer considers municipal responses to irregular migrants living in their area and in particular the significance of inclusive responses to restrictive national welfare provisions. She questions whether, as tensions in the multi-level governance on this issue suggest, inclusive responses run counter to national immigration control objectives or whether these apparently divergent approaches are in fact more coherent than the tensions between them suggest. Setting municipal service provision in its structural, demographic, governance and policy context the chapter shows that some municipal measures facilitate the regularisation of immigration status, voluntary return and compliance with national return procedures, while others contribute to shared social and economic objectives. The chapter asks why in that case national governments regularly challenge inclusive municipal measures and posits four potential reasons for further empirical investigation. In conclusion it argues that the impact of municipal measures on national policy objectives will be fundamental to resolving what the extent of irregular migrants' access to services should be. 
Looking at the different facets of irregular migrants, notably statistical definitions and realities on the ground, the (inclusionary) dynamics of labour markets and exclusionary policies, the role of local authorities and civil society, and the mobilisation of international law, this book seeks to highlight the many facets of the phenomenon of irregular migration in Europe and related conceptual and policy developments of recent years that are often neglected in public and political discourses. In the final chapter, Spencer and Triandafyllidou highlight the key themes that emerge, how they build on our understanding from earlier work, and the questions they raise for a future research agenda.

\section{References}

Bommes, M., \& Sciortino, G. (Eds.). (2011). Foggy social structures: Irregular migration, European Labour Markets and the Welfare State (IMISCOE Research Series). Amsterdam: Amsterdam University Press.

ILO. (2015). KILM 8. Employment in the informal economy. Geneva: International Labour Office. http://www.ilo.org/global/statistics-and-databases/research-and-databases/kilm/WCMS_ 422437/lang\%2D\%2Den/index.htm

Jordan, B., \& Düvell, F. (2002). Irregular migration. The dilemmas of transnational mobility. Cheltenham: Edward Elgar Publishing Limited.

Kovacheva, V., \& Vogel, D. (2009). The size of the irregular foreign resident population in the European Union in 2002, 2005 and 2008: Aggregated estimates. Hamburg: Hamburg Institute of International Economics.

Portes, A. (1978). Introduction: Toward a structural analysis of illegal (undocumented) immigration. The International Migration Review, 12(4), 469-484. https://doi.org/10.2307/2545446.

Pew Research Centre. (2019). https://www.pewresearch.org/global/2019/11/13/europes-unauthorized-immigrant-population-peaks-in-2016-then-levels-off/ last accessed on 14 January 2020.

Rosenblum, M. R., \& Ruiz Soto, A. G. (2015). An analysis of unauthorized immigrants in the United States by country and region of birth. Washington, DC: Migration Policy Institute.

Triandafyllidou, A. (Ed.). (2010). Irregular migration in Europe: Myths and realities. Aldershot: Ashgate.

UN OHCHR. (2014). The economic, social and cultural rights of migrants in an irregular situation. New York/Geneva: United Nations, Office of the High Commissioner for Human Rights.

Open Access This chapter is licensed under the terms of the Creative Commons Attribution 4.0 International License (http://creativecommons.org/licenses/by/4.0/), which permits use, sharing, adaptation, distribution and reproduction in any medium or format, as long as you give appropriate credit to the original author(s) and the source, provide a link to the Creative Commons license and indicate if changes were made.

The images or other third party material in this chapter are included in the chapter's Creative Commons license, unless indicated otherwise in a credit line to the material. If material is not included in the chapter's Creative Commons license and your intended use is not permitted by statutory regulation or exceeds the permitted use, you will need to obtain permission directly from the copyright holder.

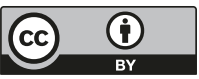

